
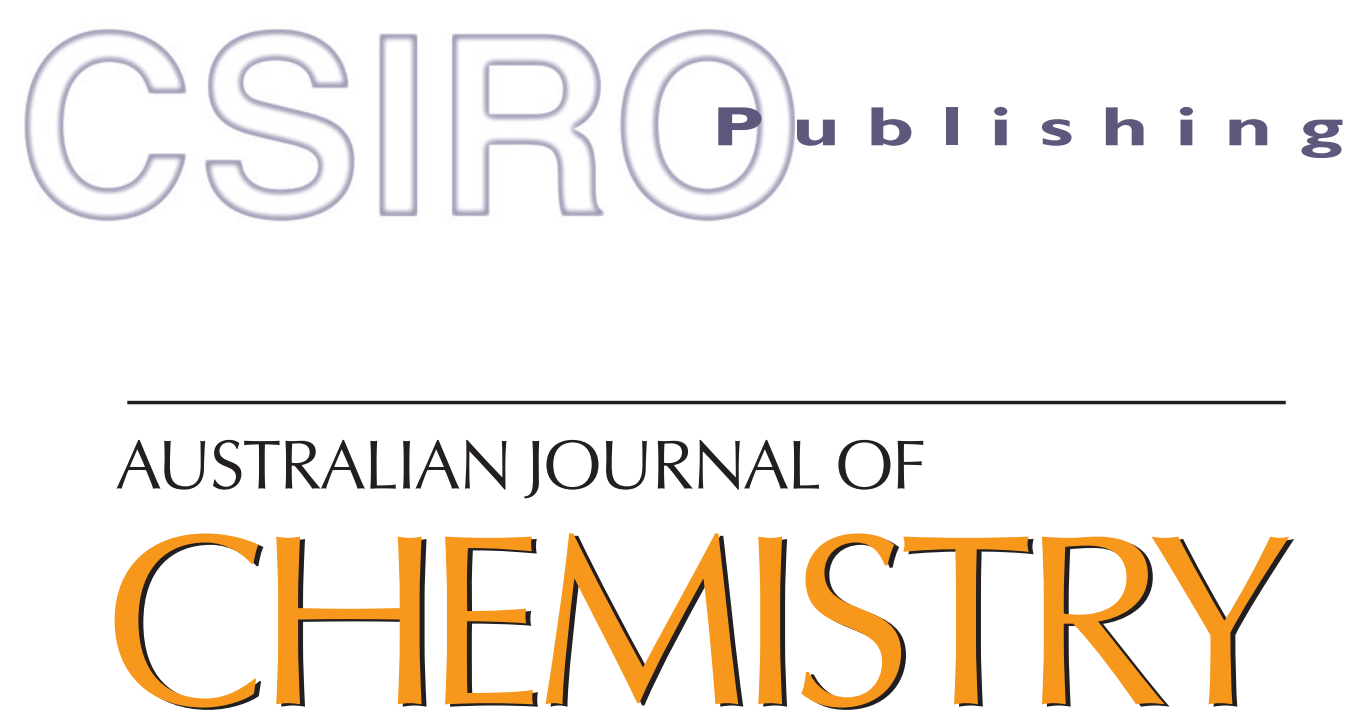

AN INTERNATIONAL JOURNAL FOR CHEMICAL SCIENCE

publishing research papers from all fields of chemical science, including synthesis, structure, new materials, macromolecules, supramolecular chemistry, biological chemistry, nanotechnology, surface chemistry, and analytical techniques.

All enquiries and manuscripts should be directed to:

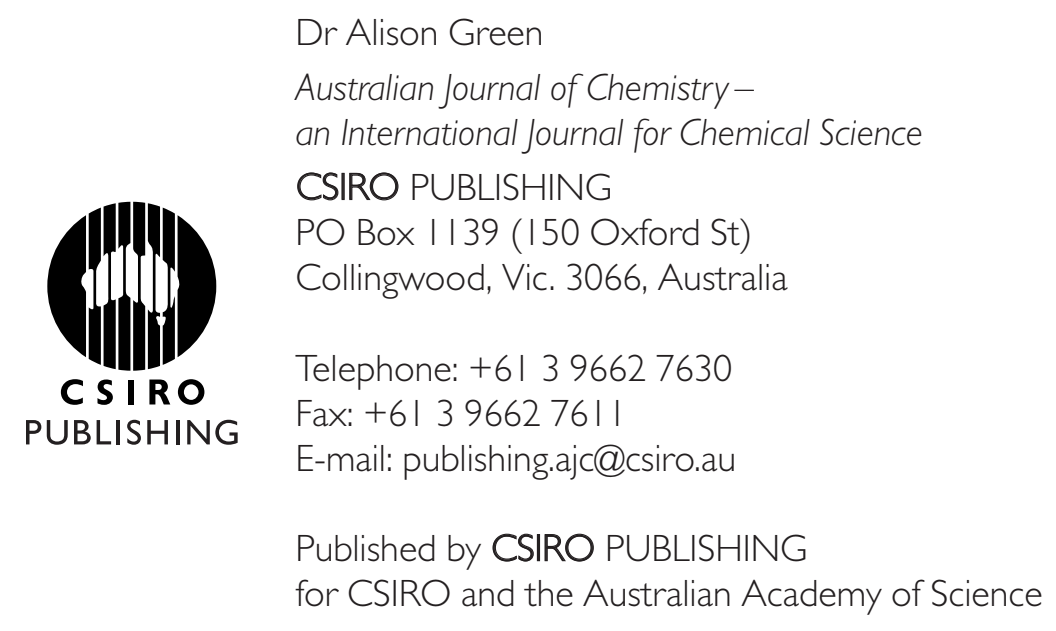

www.publish.csiro.au/journals/ajc 


\title{
Thermal Denaturation of Interfacial Protein Layers
}

\author{
S. A. Holt, ${ }^{\mathrm{A}}$ M. J. Henderson ${ }^{\mathrm{B}, \mathrm{C}}$ and J. W. White $\mathrm{B,C}$ \\ A ISIS, Rutherford Appleton Laboratory, Chilton OX11 0QX, OXON, United Kingdom. \\ ${ }^{B}$ Research School of Chemistry, The Australian National University, Canberra, A.C.T. 0200, Australia. \\ ${ }^{\mathrm{C}}$ Authors to whom correspondence should be addressed (e-mail: jww@rsc.anu.edu.au).
}

\begin{abstract}
We report for the first time the structural measurements at nanometre resolution of the denaturation of $\beta$-lactoglobulin and lysozyme at an air-water interface using the technique of neutron reflectivity. The incipient denaturation shown previously ${ }^{[1]}$ for myogloblin is also studied for these molecules at room temperature, and denaturation is provoked by increasing the temperature of the solutions progressively to $75^{\circ} \mathrm{C}$. The change in the adsorbed protein layer thickness, its scattering length density and density distribution perpendicular to the surface as a function of increased temperature are reported and the data analysed in terms of a two-state model for the denaturation process. These measurements are relevant to an understanding of the way in which proteins at interfaces act as templates, for example, in biomineralization.
\end{abstract}

Manuscript received: 9 May 2002.

Final version: 12 June 2002.

\section{Introduction}

X-Ray and neutron reflectivity measurements from free liquid surfaces and solid interfaces allow the structure of proteins at those interfaces to be probed to fractions of nanometre resolution. We have found ${ }^{[1]}$ that myoglobin adsorbed at the air-water interface is distorted by the unbalanced interfacial forces and has a density profile corresponding to the thickness of an $\alpha$-helix. We conclude that this molecule loses most of its tertiary structure but retains its secondary structure upon adsorption. For molecules more tightly bound by internal disulfide bridges, for example lysozyme, there is much less distortion.

Many techniques including film balance, ${ }^{[2,3]}$ surface radioactivity, ${ }^{[3]}$ surface potential, ${ }^{[3]}$ ellipsometry ${ }^{[3,4]}$ and circular dichroism ${ }^{[5]}$ have been used to study the structure and behaviour of biological macromolecules such as proteins. A virtue of neutron reflectivity is the ability to allow contrast variation between the self-assembled protein monolayer and the significant amounts of water that may be incorporated into the layer. This contrast is readily achieved by deuterium labelling. The technique is therefore sensitive to the distribution of protein fragments through the adsorbed layer along the surface normal direction. It confers an important advantage over ellipsometric methods for which water/protein intermixing produces an optical refractive index close to that of water. $\mathrm{Lu}$ et al. have applied neutron reflectivity to study lysozyme at the air-water ${ }^{[6]}$ and at the silica-water ${ }^{[7]}$ interface for protein concentrations of up to $4 \mathrm{~g} \mathrm{dm}^{-3}$.
In this paper we use neutron reflectivity to investigate the changes in interfacial structure of ruminant milk $\beta$-lactoglobulin and hen egg white lysozyme as a function of temperature so as to induce thermal denaturation at the interface. Our work here offers two novel features of value in studying such systems. First, denaturation in the surface layer is compared with that in the solution. Second, we are able to use the layer thickness as a good order parameter of the denaturation process.

Apart from intrinsic interest in the structural stability of surface layer proteins, a practical interest relates to the mechanism of template-induced biomineralization as it is proteins at interfaces that do this. We have shown, by X-ray and neutron reflectivity methods, ${ }^{[8,9]}$ that highly crystalline silicate films may be produced at the air-water interface with surfactant micellar structures acting as 'templates'. The methods used may allow us to understand biomineral formation, such as that of bone, shells and diatoms. These formations are natural composites of ceramic and organic phases, exhibiting high strength, and intricate architectures. The properties derive from the high level of control that biopolymers (largely proteins) exert over the nucleation and growth of crystals. In shells, the 'moving front' formation leads to dense ceramics that are formed in aqueous environments at ambient temperature.

For example, abalone shells are 3000 times stronger than the calcium carbonate component in isolation, while the proteins present in the shell comprise less than $2 \%$ of it. They nevertheless control the microarchitecture and provide the ductility and resilience of the composite; since the protein is 
at an interface we are interested to find whether it remains in its globular form, is partially denatured at the interface (as for myoglobin) or it is the protein primary structure which acts as the 'template' for shell nucleation. Figure 1 shows a scanning electron micrograph of a New Zealand abalone shell (Paua shell) at four levels of magnification. The remarkable layer-like deposition, the high regularity and the thickness of the carbonate and the protein interlayer structures show how strong the control of the protein 'template' is.

\section{Experimental}

The proteins were used as received from SIGMA or Aldrich chemicals. The $\beta$-lactoglobulin from bovine milk contains genetic variants $A$ and $\mathrm{B}$ and has a purity of greater than $95 \%$. The hen egg white lysozyme also had a purity greater than $95 \%$. Protein solutions were either 1 or $10 \mathrm{mg} \mathrm{mL}^{-1}$ in $\mathrm{D}_{2} \mathrm{O}$ or air contrast matched water (ACMW) de-aerated with high-purity nitrogen. ACMW is a mixture of $\mathrm{H}_{2} \mathrm{O}$ and $\mathrm{D}_{2} \mathrm{O}$ so that the final scattering length matches that of air. This has the advantage that when molecules adsorbed at the ACMW/air interface are examined, the signal arises entirely from the adsorbed layer. The air/ liquid interface reflectometry was performed in temperature controlled hermetically sealed troughs under a nitrogen atmosphere at $25^{\circ} \mathrm{C}$ initially, and then at a series of temperatures up to $75^{\circ} \mathrm{C}$.
The reflectivity was measured at the SURF reflectometer of the ISIS spallation neutron source at Rutherford Appleton Laboratory, Oxfordshire, U.K. This instrument was ideal for these temperaturedependent studies as it is a time-of-flight instrument with a beam approximately $2 \mathrm{~mm}$ high incident on the sample; it is therefore relatively insensitive to the liquid surface level. Similar experiments at a single wavelength angle scanning reflectometer with a small beam size would be very difficult because of the need to keep the air-liquid interface in the same geometric position to an accuracy of about 10 microns. The data were collected with the beam incident on the sample at an angle of $1.5^{\circ}$; with the wavelength range available this resulted in a $Q$ range of $0.048-0.6 \AA^{-1}$. As the samples contained significant amounts of hydrogenous material the $Q$ range was effectively limited to a maximum of about $0.25 \AA^{-1}$ before the incoherent background (ca. $4 \times 10^{-6}$ ) swamped the signal. Data Treatment

The collected data were scaled relative to a $\mathrm{D}_{2} \mathrm{O}$ scan to obtain reflectivity on an absolute scale. These data were then modelled using CXMULF, a program based on the optical transfer matrix method of classical optics. The original method is due to Abelès, ${ }^{[10]}$ adapted by Penfold, ${ }^{[11]}$ and illustrated by Brown et al. ${ }^{[8]}$ This method uses the approach that the interfacial structure can be described as one or more layers. A simulated annealing least-squares approach is then used to minimize the difference between the model and the data. The model parameters used are the film thickness $(\AA)$, scattering length density $\left(\mathrm{SLD} / \AA^{-2}\right)$ and a Gaussian interfacial roughness $(\AA)$. For these

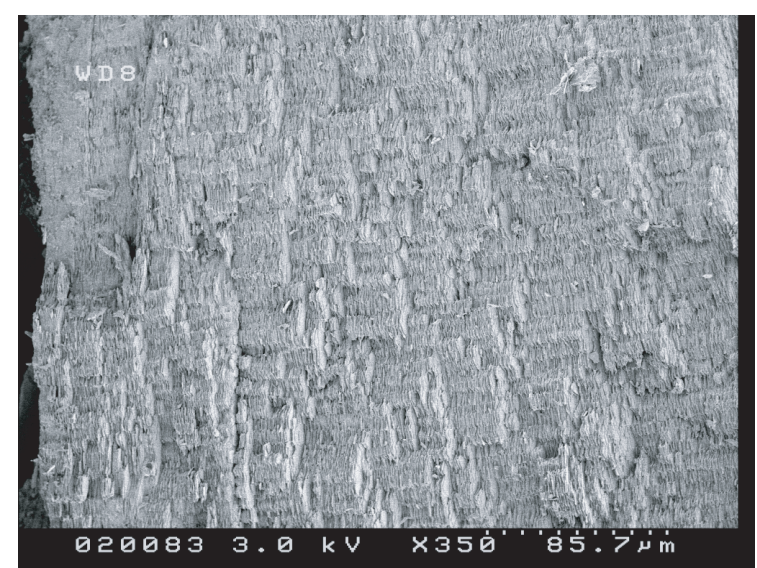

(a)

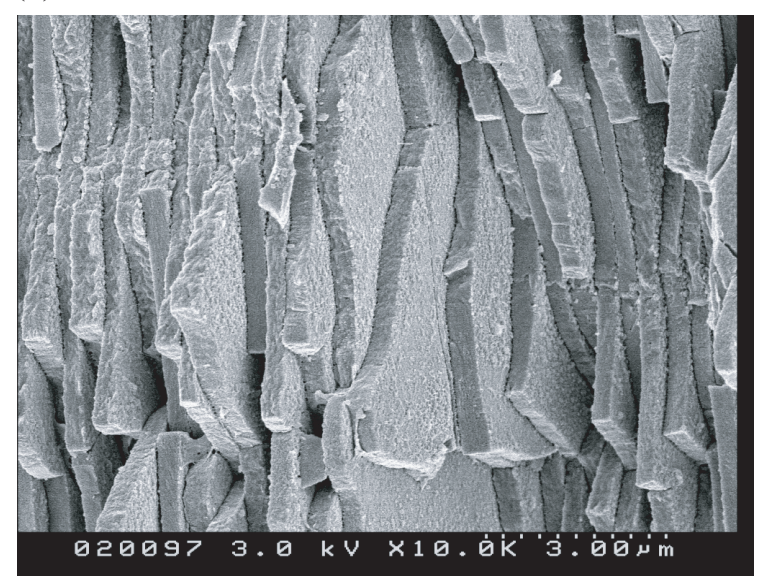

(c)

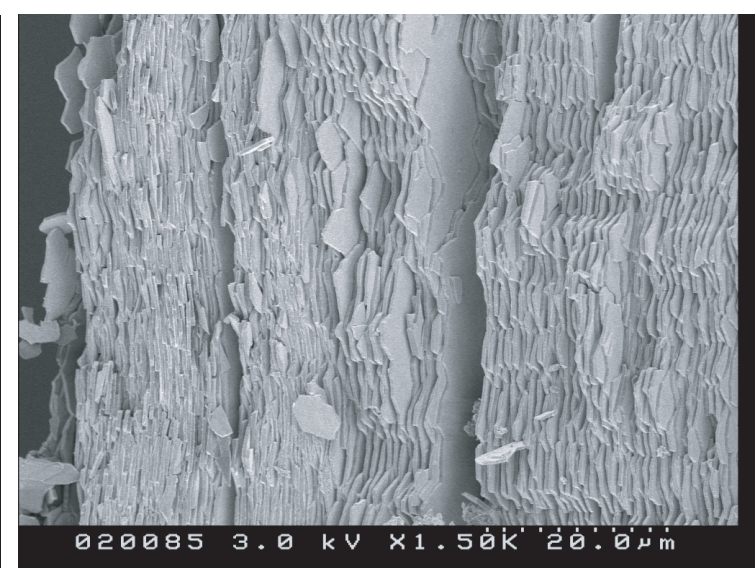

(b)

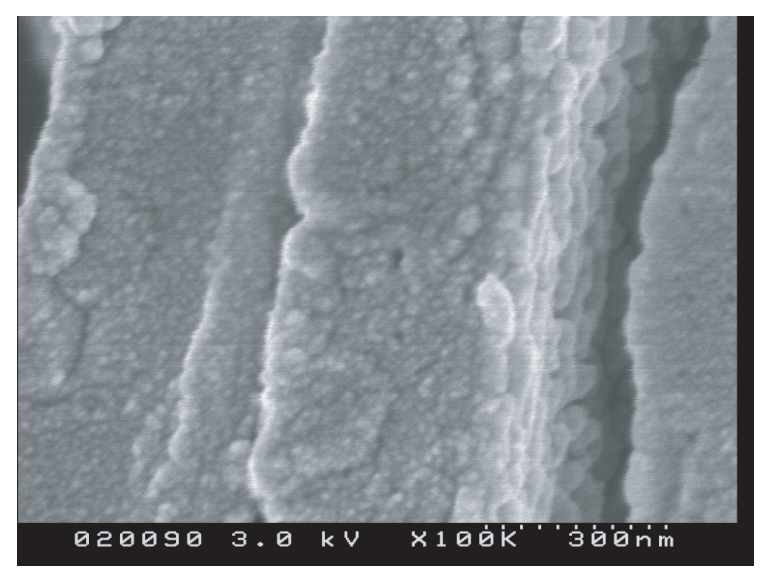

(d)

Fig. 1. Series of SEM (scanning electron microscope) images showing the nacre of a paua shell. The nacre is comprised of slabs of aragonite between a lamella protein matrix and the plates grow in stacks as can be seen in $(a)$. The sheets of aragonite are approximately $400 \mathrm{~nm}$ thick [see $(c, d)$ ], in agreement with 'critical transitions'. The bumps seen on the surface of the aragonite in $(d)$ are the same thickness as the organic matrix is reported to be (critical transition 10-50 nm). Ms Hana RobsonMarsden is gratefully acknowledged for recording the SEM images. 
experiments, the sub-phase scattering length density and the interfacial roughness were constrained, leaving only the film SLD and thickness to be fitted.

Within the proteins there are many hydrogen atoms which may exchange with deuterium when the protein is in a solution containing $\mathrm{D}_{2} \mathrm{O}$. For each residue the number of exchangeable proteins is known; ${ }^{[12]}$ therefore one can calculate an SLD which takes into account the solvent that the protein has been solubilized into. After preparation the solutions were allowed to equilibrate for excess of $24 \mathrm{~h}$; we therefore assume in our calculations that all of the exchangeable protons had in fact exchanged. We also calculate the SLD for the 'pure' protein, that is, we do not include any contributions for water molecules within the structure. The protein volume and density have been calculated only from the mass and volume ${ }^{[13]}$ of the individual protein residues. This approach then enables us in a first approximation to make an estimate of the protein proportion of the fitted interfacial layers from a comparison of the fitted SLD and the calculated SLD.

More detailed information regarding the protein/sub-phase contributions to the scattering can readily be obtained when data are acquired from an ACMW sub-phase, where the surface excess of the protein can be determined directly. In this case there is no contribution from any solvent associated with the protein visible to the neutron beam, and thus the total contribution to the SLD is that provided by the protein. The surface excess $\left(\Gamma, \mathrm{g} \mathrm{m}^{-2}\right)$ can then be determined as:

$$
\Gamma=\frac{10^{20} M_{\mathrm{w}} \rho_{\mathrm{b}} \tau}{N_{\mathrm{A}} \sum b_{\text {prot }}}
$$

in which $M_{\mathrm{w}}$ is the molecular mass of the protein $\left(\mathrm{g} \mathrm{mol}^{-1}\right) ; \rho_{b}$ is the measured SLD of the layer $\left(\AA^{-2}\right)$; $\tau$ is the thickness of the layer $(\AA)$; and $\Sigma b_{\text {prot }}$ is the sum of the scattering lengths of the elements which make up the protein, allowing for any isotopic exchange $(\AA)$.

When the experiment is carried out on a $\mathrm{D}_{2} \mathrm{O}$ sub-phase it is impossible to determine the contribution of the material at the surface layer distinct from that of interpenetrating sub-phase molecules without information about volumes of the particles at the surface. In terms of proteins, if it can be assumed that the protein has not denatured at the surface then the scattering length density of the protein $\left(\rho_{b, \text { prot }}, \AA^{-2}\right)$ can be calculated from the equation:

$$
\rho_{b, \text { prot }}=\frac{\sum b_{\text {prot }}}{V_{\text {prot }}}
$$

in which $V_{\text {prot }}$ refers to the volume occupied by the protein, from its solution dimensions $\left(\AA^{3}\right)$. This then enables the proportion of the surface taken up by the protein $(x)$ to be determined as the measured scattering length density of the solution is made up of the contributions from the protein and the sub-phase.

$$
\rho_{b, \text { tot }}=(1-x) \rho_{b, \mathrm{D}_{2} \mathrm{O}}+x \rho_{b, \text { prot }}
$$

Once the fraction of the surface which consists of protein has been determined the surface excess of the protein can be calculated using also the measured thickness of the layer and the following equation:

$$
\Gamma=\frac{10^{20} M_{\mathrm{w}} x \tau}{N_{\mathrm{A}} V_{\text {prot }}}
$$

From the area per molecule and the layer thickness, it is possible to gain an insight into the arrangement of the protein units.

\section{Results}

\section{Time Dependence of the Interface Structure at $25^{\circ} \mathrm{C}$}

As a starting point for the experiments, the neutron reflectivity from the protein solutions at $25^{\circ} \mathrm{C}$ was studied soon after making up the solutions and several hours later. A lysozyme solution at $1 \mathrm{mg} \mathrm{mL}^{-1}$ in ACMW at $\mathrm{pH} 2$ and a $1 \mathrm{mg} \mathrm{mL}^{-1} \beta$-lactoglobulin solution at $\mathrm{pH} 2$ were measured. Figure 2 shows the reflectivity from the lysozyme solution initially (lower curve) and after $5 \mathrm{~h}$ (upper curve). The scattering length density profiles for these two experiments are also shown. The lower (full curve) is for the data obtained immediately after the solution was placed into the reflectometer trough, and the dotted curve shows the profile after $5 \mathrm{~h}$. The initial, somewhat broader, monolayer at the
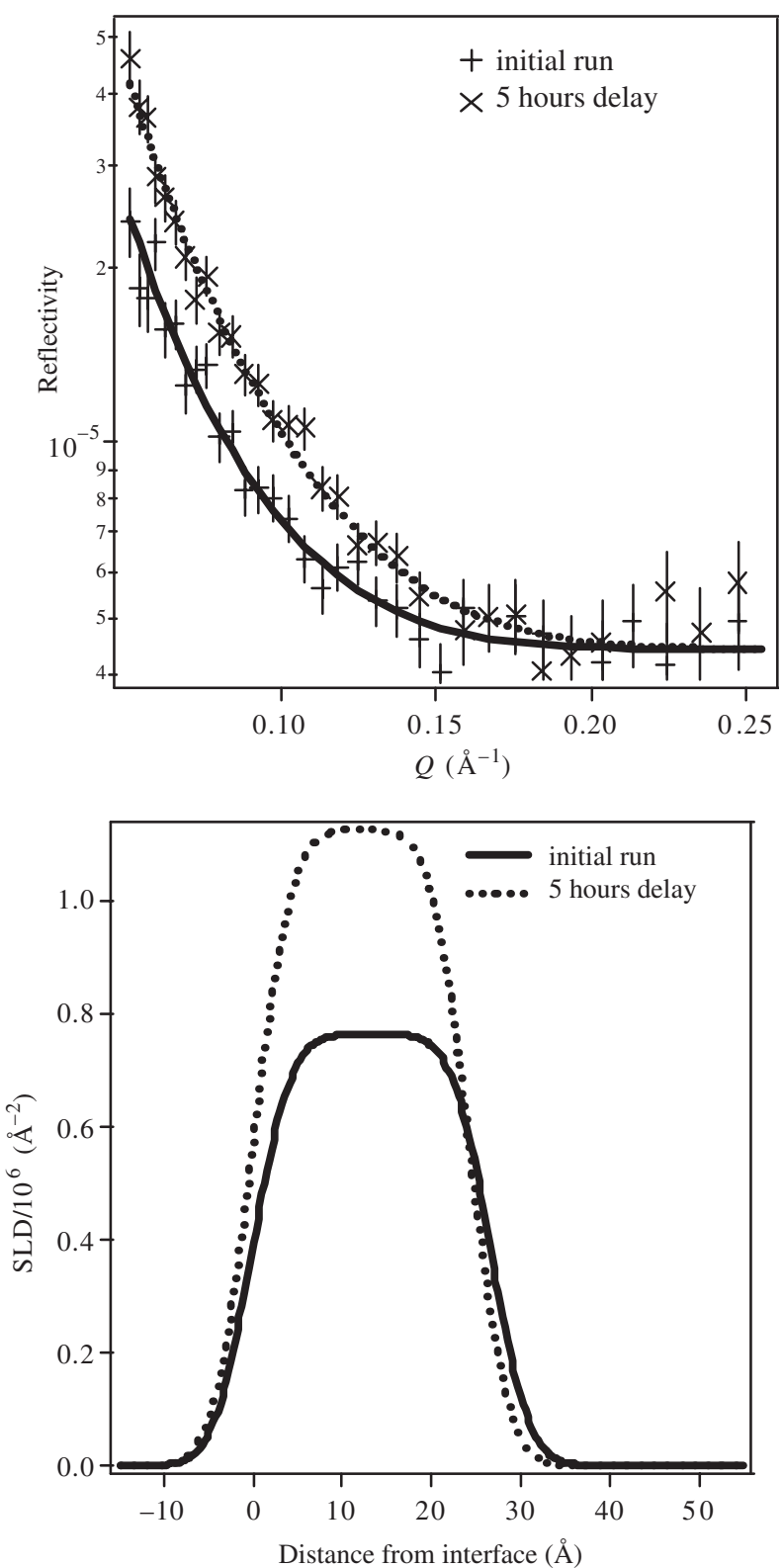

Fig. 2. Reflectivity and fit from lysozyme solutions at $1 \mathrm{mg} \mathrm{mL} L^{-1}$, $\mathrm{pH} 2.0$, when first added to the trough and $5 \mathrm{~h}$ later. 
air-water interface 'heals' and becomes sharper and more reflective with time.

The analogous data for $1 \mathrm{mg} \mathrm{mL} \mathrm{mL}^{-1} \beta$-lactoglobulin solutions at $\mathrm{pH} 2$, again in ACMW, are shown in Figure 3. There is a small change in reflectivity, possibly in the opposite sense to that for lysozyme. The reflectivity for the surface which was exposed for $6.5 \mathrm{~h}$ may be slightly lower than that of the freshly prepared solution. The corresponding scattering length density profile also shown in Figure 3 for the aged solution (dotted line) is somewhat broader and of slightly lower intensity than that for the fresh material.

To a first approximation, 'healing' of the lysozyme film is greater than that for the $\beta$-lactoglobulin.
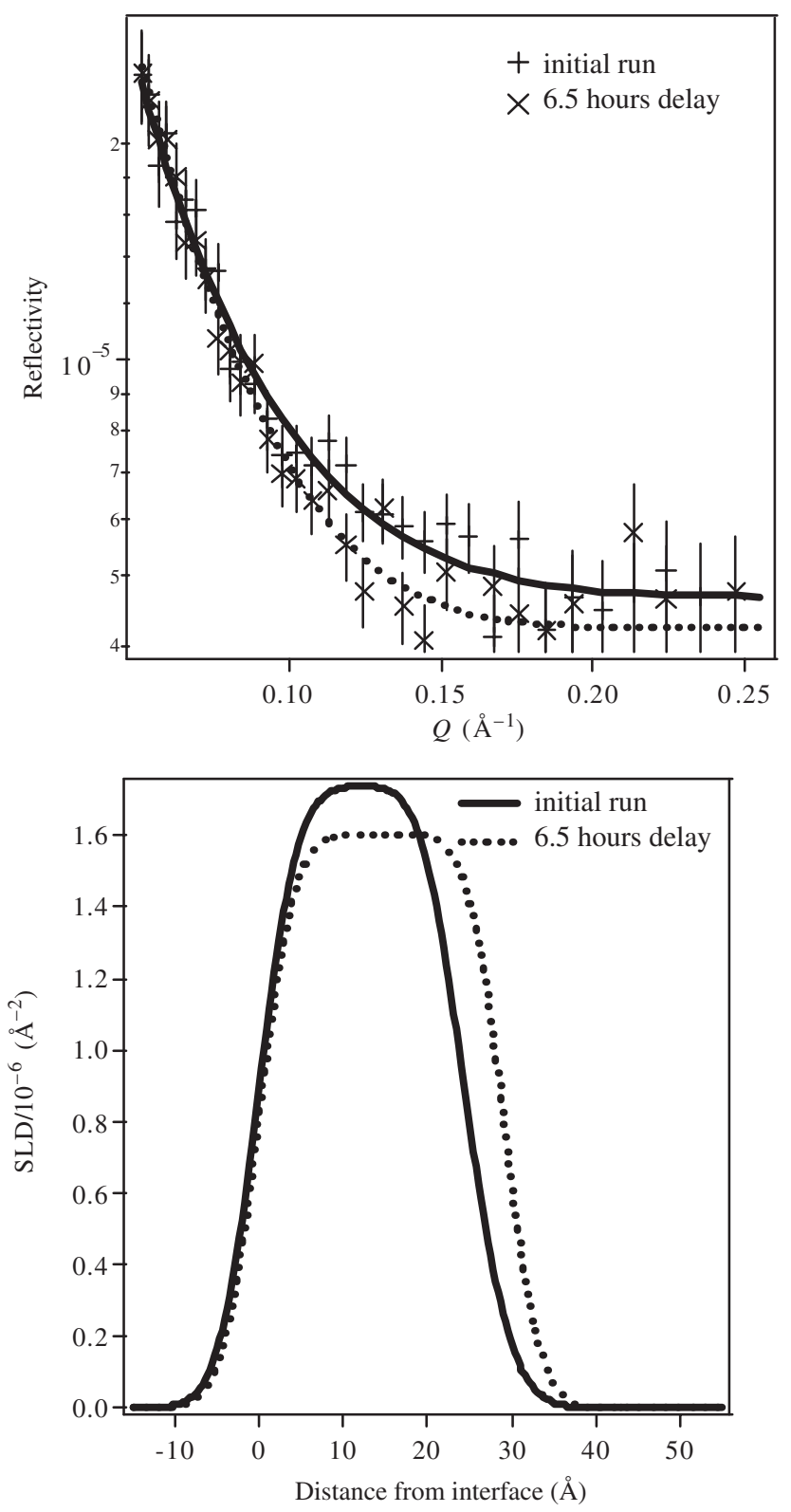

Fig. 3. Reflectivity and fit from $\beta$-lactoglobulin solutions at $1 \mathrm{mg}$ $\mathrm{mL}^{-1}, \mathrm{pH} 2.0$, in ACMW, when first added to the trough and $6.5 \mathrm{~h}$ later.

\section{Temperature Dependence of the Reflectivity}

\section{Lysozyme}

The most important qualitative result is that measurements were possible at all with the reflectometer up to $75^{\circ} \mathrm{C}$. Good precision in fitting the reflectivity curves enabled the calculation of a scattering length density profile for each protein adsorbed at the air interface ACMW system at $\mathrm{pH} 2$. The data are summarized in Table 1 for a model that comprises of a single layer of the protein at the air-water interface. Multiple-layer fits were not needed for lysozyme concentrations of $1 \mathrm{mg} \mathrm{mL}^{-1}$ or less.

Table 1 shows that the fitted scattering length density for lysozyme in ACMW is about $1.1 \times 10^{-6} \AA^{-2}$, compared with a calculated value of $2.15 \times 10^{-6}$ in ACMW, putting an upper limit of about $50 \%$ on the protein fraction of the monolayer. Su et al. ${ }^{[14]}$ obtain a volume fraction of 0.45 for a single layer of lysozyme from a $\mathrm{pH} 4.0$ solution at a solid/liquid interface. If we calculate an SLD for lysozyme based upon the crystal structure volume, we attain an SLD of $0.91 \times 10^{-6} \AA^{-2}$ (ACMW exchange). The inclusion of water within the lysozyme, allowing for exchange, further increases the SLD to $0.92 \times 10^{-6}$ and $1.10 \times 10^{-6} \AA^{-2}$ for 100 and 2000 water molecules respectively. We consider it unlikely that the adsorbed layer would correspond to a densely packed monolayer of lysozyme, with no associated sub-phase. The SLD calculations undertaken using the protein residue volumes are therefore valid and are used exclusively throughout the paper.

The SLD of the lysozyme layer then increases slightly to $1.3 \times 10^{-6} \AA^{-2}$ (protein volume fraction ca. 70\%). Beyond $55^{\circ} \mathrm{C}$, the SLD decreases below the initial value indicating that there is a gradual increase in the proportion of sub-phase 'within' the protein at the interface. The model parameters are displayed in Figure 4. Focusing on the layer thickness, it appears that this might be a good order parameter for the denaturation process and we use it below for analysis of the denaturation. At low temperatures, the layer thickness is as expected for lysozyme at the concentration used. As the temperature rises, however, the layer thickness increases, gradually following a sigmoidal behaviour, to a thickness of about $150 \%$ greater than the starting value. There is some

Table 1. One-layer fits for the $1 \mathrm{mg} \mathrm{mL}^{-1}$ lysozyme, $\mathrm{pH} 2.0$, in ACMW

\begin{tabular}{clccl}
\hline Temp. $\left({ }^{\circ} \mathrm{C}\right)$ & $d_{1}(\AA)$ & $\mathrm{SLD} / 10^{-6}\left(\AA^{-2}\right)$ & Background $/ 10^{-6}$ & $\chi^{2}$ \\
\hline 25 & $24(1)$ & $1.12(4)$ & $4.4(1)$ & 0.8070 \\
30 & $24(2)$ & $1.21(6)$ & $4.6(2)$ & 0.7885 \\
35 & $31(1)$ & $1.25(3)$ & $6.0(2)$ & 1.34 \\
40 & $32(1)$ & $1.36(2)$ & $5.8(2)$ & 1.093 \\
45 & $33(1)$ & $1.32(2)$ & $6.2(2)$ & 1.227 \\
50 & $39(1)$ & $1.13(2)$ & $6.6(2)$ & 0.9515 \\
55 & $37(1)$ & $1.02(2)$ & $5.5(2)$ & 1.144 \\
60 & $37.3(3)$ & $0.74(2)$ & $4.0(1)$ & 1.139 \\
65 & $37.3(3)$ & $0.89(1)$ & $4.7(1)$ & 0.5667 \\
70 & $37(4)$ & $0.43(2)$ & $4.4(1)$ & 1.120 \\
\hline
\end{tabular}




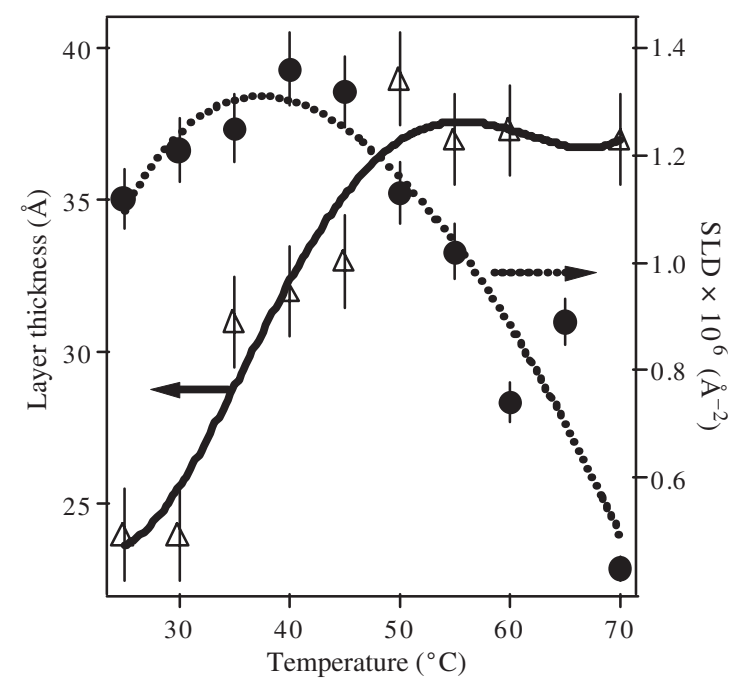

Fig. 4. Model parameters from lysozyme at $\mathrm{pH} 2.0,1 \mathrm{mg} \mathrm{mL}^{-1}$, in ACMW as a function of temperature. (Line is a guide to the eye.)

evidence of an intermediate process at temperatures near $40^{\circ} \mathrm{C}$.

A good indication of the density of material at the airwater interface is given by the surface excess. Figure 5 shows this for the $1.0 \mathrm{mg} \mathrm{mL}^{-1}$ lysozyme system at $\mathrm{pH} 2$ in ACMW. The maximum surface excess occurs at about $45^{\circ} \mathrm{C}$. This is a lower temperature than the bulk denaturation temperature found for the wild type of lysozyme, ${ }^{[15]}$ and is somewhat higher than the denaturation temperature for the Ral56Tmr variant lysozyme studied by ultraviolet circular dichroism at $205 \mathrm{~nm}$ wavelength. The data suggest that it has been possible by the technique of neutron reflectivity to measure the denaturation process in a $50 \AA$ surface layer of lysozyme.

Measurements were also made in heavy water on lysozyme solutions at $10 \mathrm{mg} \mathrm{mL}^{-1}$ and $\mathrm{pH} 7$ to detect qualitatively any effects of protein concentration on the degree of deuteration of the substrate and $\mathrm{pH}$. Again, good one-layer fits were obtained up to $55^{\circ} \mathrm{C}$, beyond which single-layer fits were no longer acceptable (Table 2). The data show that the initial surface film is already a layer of about $37 \AA$, approximately equal to the thickness of the film formed after denaturation at high temperature with the $1 \mathrm{mg} \mathrm{mL}^{-1}$ solution at $\mathrm{pH} 2$. This thick layer also has a large scattering length density. If all of the exchangeable hydrogen atoms on the lysozyme were exchanged, the scattering density for the protein would be about $3.5 \times 10^{-6} \AA^{-2}$. The fitted profile therefore indicates that the surface layer is approximately $75 \%$ heavy water and $25 \%$ protein. This leads to a calculation of about $1000 \mathrm{D}_{2} \mathrm{O}$ molecules per lysozyme molecule. It should be noted that the quality of fit of this model to the experimental data at all of the temperatures up to $55^{\circ} \mathrm{C}$ is quite acceptable. The data are displayed graphically in Figure 6.

The protein layer thickness remains approximately constant at about $37 \AA$ up to a temperature of the order of $50^{\circ} \mathrm{C}$, whereupon a sharp increase in thickness occurs. Taking the layer thickness as the order parameter for the denaturation process, the midpoint of its change is at about

Table 2. One-layer fits (where appropriate) for the $10 \mathrm{mg} \mathrm{mL}^{-1}$ lysozyme, $\mathrm{pH} 7.0$, in $\mathrm{D}_{\mathbf{2}} \mathrm{O}$

\begin{tabular}{clccc}
\hline Temp. $\left({ }^{\circ} \mathrm{C}\right)$ & $d_{1}(\AA)$ & $\mathrm{SLD} / 10^{-6}\left(\AA^{-2}\right)$ & Background $/ 10^{-6}$ & $\chi^{2}$ \\
\hline 25 & $37.2(7)$ & $5.65(1)$ & $2.7(1)$ & 1.653 \\
30 & $36.6(7)$ & $5.65(1)$ & $2.7(1)$ & 1.370 \\
35 & $34.4(8)$ & $5.72(2)$ & $2.7(1)$ & 0.9297 \\
40 & $34.9(8)$ & $5.73(1)$ & $3.6(1)$ & 0.9100 \\
45 & $37.3(8)$ & $5.78(1)$ & $3.6(1)$ & 1.023 \\
50 & $38.5(9)$ & $5.80(1)$ & $3.6(1)$ & 1.334 \\
$55^{\mathrm{A}}$ & $51(2)$ & $5.74(3)$ & $3.0(2)$ & 2.640 \\
$60^{\mathrm{A}}$ & $49(1)$ & $5.57(3)$ & $3.0(2)$ & 5.637 \\
\hline
\end{tabular}

A One-layer fit no longer acceptable.

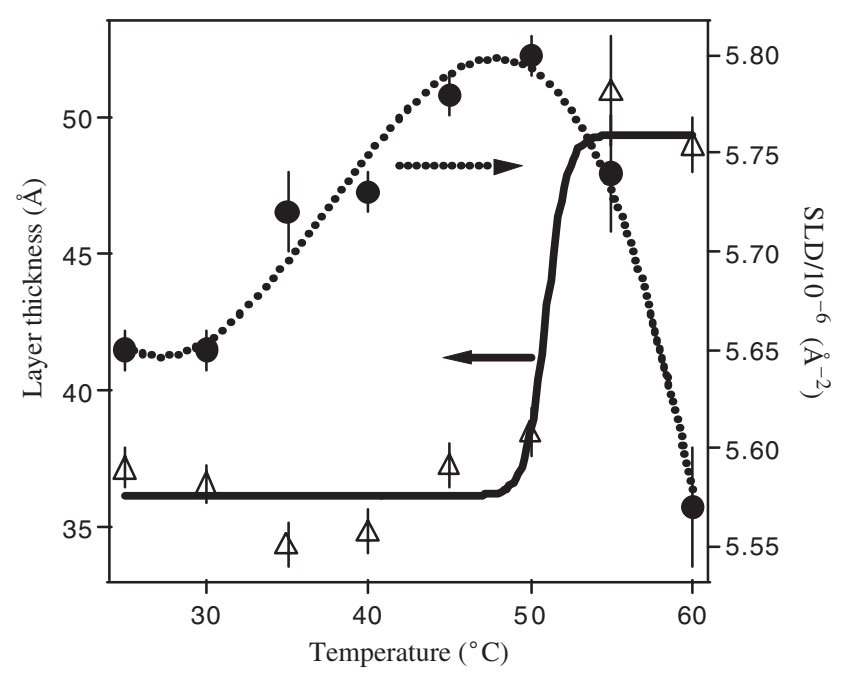

Fig. 6. Model parameters for one-layer fits to $10 \mathrm{mg} \mathrm{mL} \mathrm{mL}^{-1}$ lysozyme in $\mathrm{D}_{2} \mathrm{O}, \mathrm{pH}$ 7.0. (Line is a guide to the eye.)
Fig. 5. Surface excess from lysozyme at $\mathrm{pH} 2.0,1 \mathrm{mg} \mathrm{mL} L^{-1}$, in ACMW. (Line is a guide to the eye.)

(1)

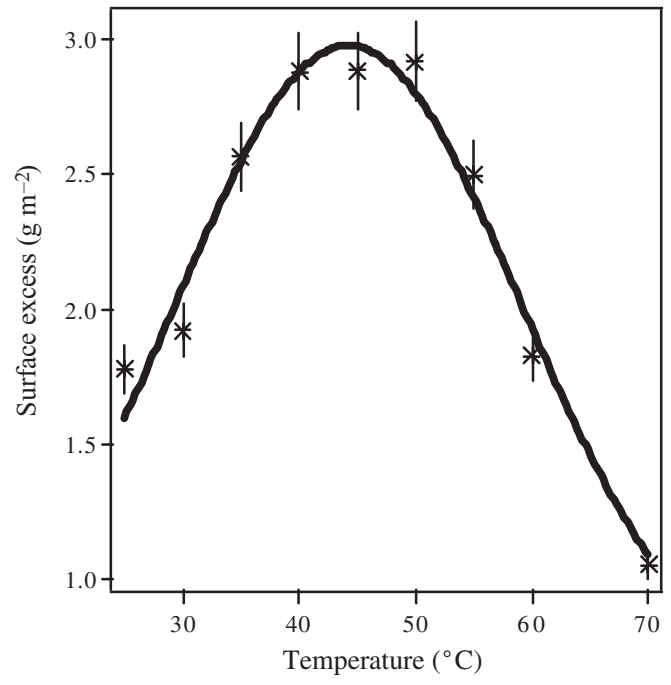


Table 3. Two-layer fits (where appropriate) for the $10 \mathrm{mg} \mathrm{mL}^{-1}$ lysozyme, $\mathbf{p H} 7.0$, in $\mathrm{D}_{2} \mathrm{O}$ Note that sub-phase SLD $=6.35 \times 10^{-6}\left(\AA^{-2}\right)$

\begin{tabular}{ccccccc}
\hline $\begin{array}{c}\text { Temp. } \\
\left({ }^{\circ} \mathrm{C}\right)\end{array}$ & $\begin{array}{c}d_{1} \\
(\AA)\end{array}$ & $\begin{array}{c}\mathrm{SLD}_{1} / 10^{-6} \\
\left(\AA^{-2}\right)\end{array}$ & $\begin{array}{c}d_{2} \\
(\AA)\end{array}$ & $\begin{array}{c}\mathrm{SLD}_{2} / 10^{-6} \\
\left(\AA^{-2}\right)\end{array}$ & Background $/ 10^{-6}$ & $\chi^{2}$ \\
\hline 50 & $36(2)$ & $5.7(2)$ & $29(6)$ & $6.22(7)$ & $3.9(5)$ & 1.020 \\
55 & $36(2)$ & $5.7(2)$ & $27(2)$ & $5.95(5)$ & $4.1(5)$ & 1.338 \\
60 & $36(2)$ & $5.38(2)$ & $31(1)$ & $5.85(3)$ & $3.5(2)$ & 1.245 \\
65 & $35(1)$ & $4.92(2)$ & $31(1)$ & $5.77(3)$ & $2.4(2)$ & 1.866 \\
70 & $31(1)$ & $5.26(3)$ & $38(1)$ & $5.88(3)$ & $4.0(2)$ & 1.010 \\
\hline
\end{tabular}

$53^{\circ} \mathrm{C}$. This is considerably higher than for the monolayer system.

In an attempt to make the fitting of the high-temperature and the low-temperature data consistent, two-layer fits were tried for both temperature ranges. The results from these are summarized in Table 3. Below $50^{\circ} \mathrm{C}$, the two-layer fits were not very useful, the second layer having an SLD only 3\% different from the sub-phase. At $55^{\circ} \mathrm{C}$ and higher, the quality of the fits was markedly improved by the addition of a second layer. The upper layer (closer to the air-water interface) gives a thickness of about $35 \AA$ from 50 to $70^{\circ} \mathrm{C}$, similar to the low-temperature results from the one-layer models. The second layer underneath it has a scattering density almost indistinguishable from the sub-phase at $50^{\circ} \mathrm{C}$; as the temperature is increased the SLD of this layer decreases as more material is adsorbed from solution. Inspection of the main features of these variations (Figs 6 and 7) reveals that significant changes in order occur at about $55^{\circ} \mathrm{C}$ and possibly between 30 and $40^{\circ} \mathrm{C}$. The interfacial denaturation of lysozyme is clearer for the $1 \mathrm{mg} \mathrm{mL}^{-1}$ data than for the $10 \mathrm{mg} \mathrm{mL}^{-1}$ system, where the interfacial changes are complicated by the adsorption of more material from solution which may already be partially denatured.

\section{$\beta$-Lactoglobulin}

The thermal denaturation of this protein at the air-water interface of ACMW at $\mathrm{pH} 2$ was studied first at 25 and $65^{\circ} \mathrm{C}$. The reflectivity functions at low temperature (circles) and at $65^{\circ} \mathrm{C}$ (triangles) are shown in Figure 8 along with the corresponding scattering length density profiles at these temperatures. The difference in the reflectivity curves is clear, that of the high temperature being more reflective, particularly at low $Q$ values. Only a two-layer fit was appropriate to the high temperature. The parameters are summarized in Table 4. Figure 8 shows that in real space the reflectivity of the layer closest to the air-water interface (layer 1) is stronger because the scattering length density is higher and that there is a second layer beyond about $35 \AA$.

Experiments were also performed with $\beta$-lactoglobulin at $\mathrm{pH} 7$ (the dimerized state) in ACMW over a range of temperatures. The data are displayed graphically in Figure 9 and summarized in Table 5. Quite good fits to a one-layer model were found at all temperatures up to $65^{\circ} \mathrm{C}$. There was a progressive increase in layer thickness from $28 \AA$ up to 45 $\AA$ at the highest temperature. Associated with this, the
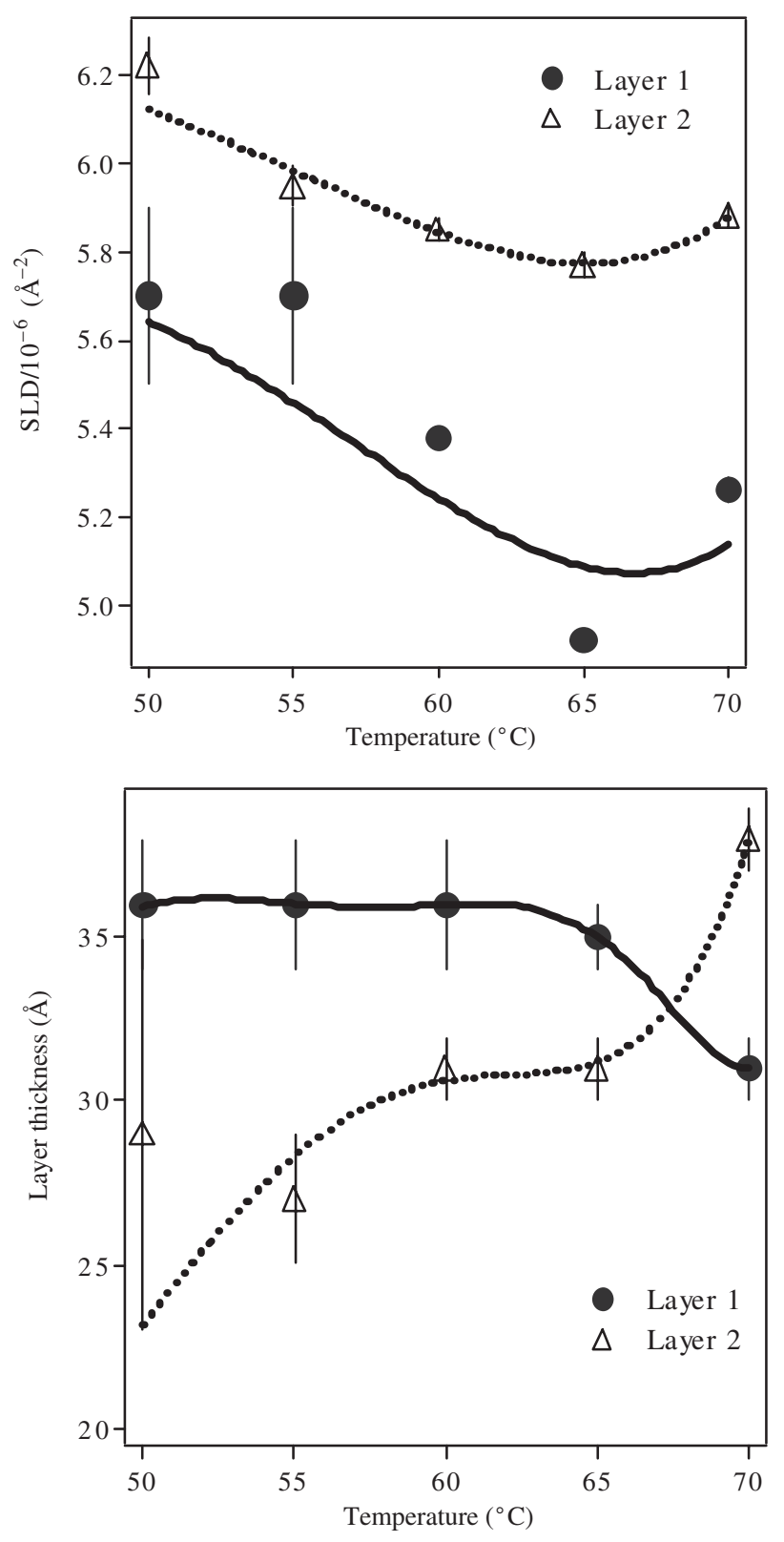

Fig. 7. Model parameters for two-layer fits to $10 \mathrm{mg} \mathrm{mL}-1$ lysozyme in $\mathrm{D}_{2} \mathrm{O}, \mathrm{pH}$ 7.0. (Line is a guide to the eye.)

scattering length density up to about $45^{\circ} \mathrm{C}$ indicated densification of the film but, at higher temperature, entry of zero scattering length density ACMW into the film structure was observed. These data are consistent with at least partial unravelling of the protein structure above $55^{\circ} \mathrm{C}$. This result is also reflected in the surface excess which shows a maximum at about $45^{\circ} \mathrm{C}-$ a temperature which we can take to be an indication of the surface denaturation temperature for this protein.

\section{Discussion}

In this section we first review the literature studies of the denaturation of $\beta$-lactoglobulin and lysozyme in solution and then analytically fit the profiles of the change in surface layer 

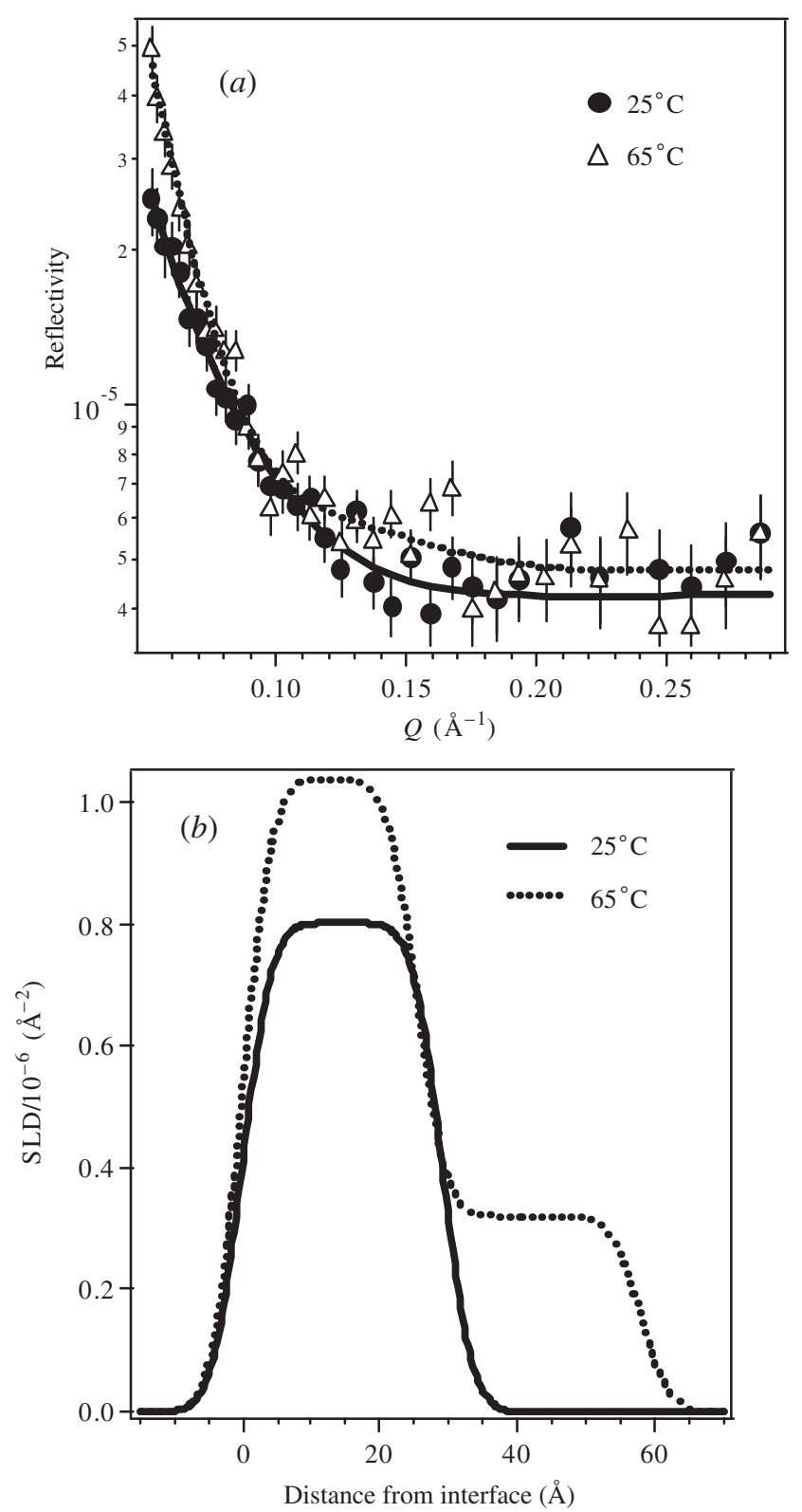

Fig. 8. $\beta$-Lactoglobulin adsorbed at the air-liquid interface: (a) reflectivity profiles at 25 and $65^{\circ} \mathrm{C}$ where the line is the fit to the data; and (b) SLD profiles corresponding to the fits.

Table 4. One- and two-layer fits for $1 \mathbf{~ m g ~ m L}^{-1} \beta$-lactoglobulin, pH 2.0, in ACMW, as a function of temperature

\begin{tabular}{ccccccc}
\hline $\begin{array}{c}\text { Temp. } \\
\left({ }^{\circ} \mathrm{C}\right)\end{array}$ & $\begin{array}{c}d_{1} \\
(\AA)\end{array}$ & $\begin{array}{c}\mathrm{SLD}_{1} / 10^{-6} \\
\left(\AA^{-2}\right)\end{array}$ & $\begin{array}{c}d_{2} \\
(\AA)\end{array}$ & $\begin{array}{c}\mathrm{SLD}_{2} / 10^{-6} \\
\left(\AA^{-2}\right)\end{array}$ & Background $/ 10^{-6}$ & $\chi^{2}$ \\
\hline 25 & $29(3)$ & $0.78(3)$ & - & - & $4.2(1)$ & 0.7037 \\
65 & $26(8)$ & $0.95(4)$ & 32 & $(3)$ & $4.8(2)$ & 1.076 \\
\hline
\end{tabular}

protein thickness with temperature. For this we used the approach of DeKoster et al. ${ }^{[16]}$ Fitting the data in this way gives an enthalpy for the denaturation process assuming a two-state model. Finally, we consider the relationship between the change in layer thickness and the change in surface area of the low-temperature and high-temperature states of the protein at the interface.
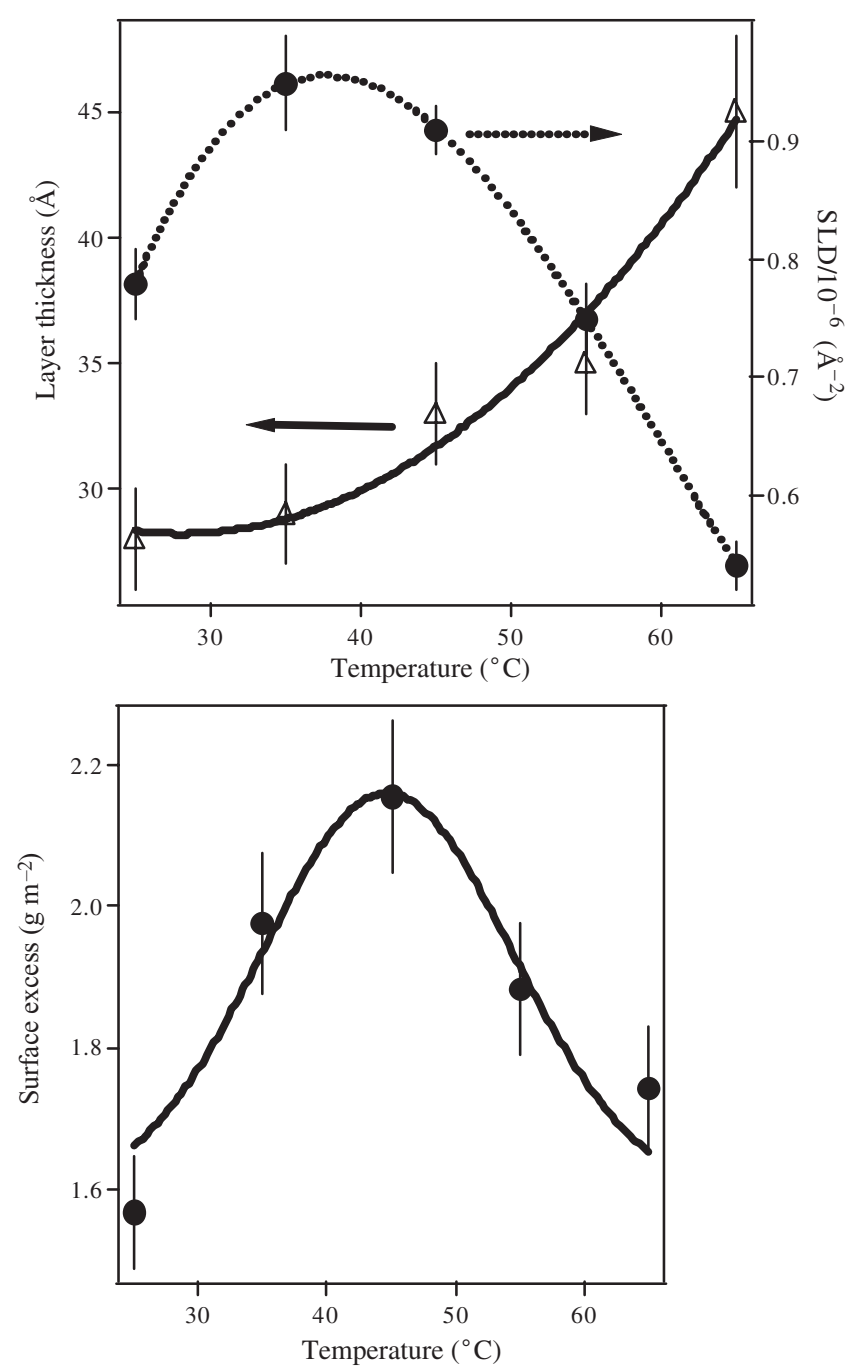

Fig. 9. Model parameters from fits to $1 \mathrm{mg} \mathrm{mL}^{-1} \beta$-lactoglobulin, $\mathrm{pH}$ 7.0, in ACMW as a function of temperature. (Line is a guide to the eye.)

Table 5. One-layer fits for $1 \mathrm{mg} \mathrm{mL}^{-1} \beta$-lactoglobulin, $\mathrm{pH}$ 7.0, in ACMW, as a function of temperature

\begin{tabular}{ccccc}
\hline Temp. $\left({ }^{\circ} \mathrm{C}\right)$ & $d_{1}(\AA)$ & $\mathrm{SLD}_{1} / 10^{-6}\left(\AA^{-2}\right)$ & Background $/ 10^{-6}$ & $\chi^{2}$ \\
\hline 25 & $35(2)$ & $0.53(2)$ & $3.2(1)$ & 0.6724 \\
25 & $28(2)$ & $0.78(3)$ & $4.2(1)$ & 0.7355 \\
35 & $29(2)$ & $0.95(4)$ & $5.5(1)$ & 0.6433 \\
45 & $33(2)$ & $0.91(2)$ & $6.4(2)$ & 1.081 \\
55 & $35(2)$ & $0.75(3)$ & $5.9(2)$ & 0.174 \\
65 & $45(3)$ & $0.54(2)$ & $4.9(1)$ & 0.9438 \\
\hline
\end{tabular}

\section{Ruminant Milk $\beta$-Lactoglobulin}

$\beta$-Lactoglobulin from ruminant milk is a globular protein with an $M_{\mathrm{w}}$ of $18.3 \mathrm{kD}$. It has 162 amino acids and exists as a dimer at physiological $\mathrm{pH}$ values. $\beta$-Lactoglobulin is predominantly constituted of $\beta$-sheets $(50 \%$ of the secondary structures) and contains $\alpha$-helix (10\% of the secondary structures). Native $\beta$-lactoglobulin has two disulfide bonds and one free thiol group, which is buried within the protein structure. Four out of the five cysteine residues form two 
disulfide bridges, 66-160 and 106-119, leaving Cys121 as the free thiol that appears to be responsible, through disulfide interchange, for the formation of covalent aggregates upon heating. ${ }^{[17]}$

\section{Hen Egg White Lysozyme}

Lysozyme contains 129 residues with an $M_{\mathrm{w}}$ of $14.4 \mathrm{kDa}$. The lysozyme molecule can be divided into an $\alpha$-helical and a $\beta$-sheet domain with the active site cleft between them. The $\alpha$-helical domain consists of residues $1-35$ and 85-129 which contains four $\alpha$-helices and a short 310 -helix. The $\beta$-sheet domain consists of residues 36-84 that form a threestranded antiparallel $\beta$-sheet, a long loop and a 3 -helix. The conserved long loop has a disulfide at its base, disulfide 64-80, and a second disulfide pins the loop to the third $\alpha$-helix, disulfide $76-94 .^{[18]}$

\section{Denaturation in the Bulk}

$\beta$-Lactoglobulin is the major whey protein in bovine milk. It has 162 amino acids and molecular weight of 18298 (genetic variant $\mathrm{A}$ ). The genetic variant $\mathrm{B}$ has a molecular mass of 18212 and there are two disulfide bridges. The overall structure is in the form of an eight-stranded $\beta$-barrel. Thermal denaturation experiments in bulk solution have been done on all variants, the temperature of the inflection point in the denaturation curve ranging from 72 to $76^{\circ} \mathrm{C}$.

In studies of the temperature denaturation of lysozyme in the bulk, Green et al. ${ }^{[19]}$ and others ${ }^{[20]}$ have suggested that two distinct transitions can be identified. These proteins in solution change conformation first at a lower temperature and then subsequently denature when the temperature is raised. The first transition is characterized by an increase in viscosity of the solution, which in turn is related to the increase in molecular dimensions. For lysozyme, the first transition occurs sharply at about $50^{\circ} \mathrm{C}$ and the second at approximately $70^{\circ} \mathrm{C}$. The work of Green et al. ${ }^{[19]}$ was done at a protein concentration of $100 \mathrm{mg} \mathrm{mL}$, well above the concentrations used in the present experiments. Following Clarke et al., ${ }^{[21]}$ the changes observed in the infrared spectra for the bulk solution indicate formation of anti-parallel $\beta$-sheet structures as a precursors to bulk gelation. Green et al. ${ }^{[19]}$ also observed that, at $50^{\circ} \mathrm{C}$, complete unfolding occurred if lysozyme was incubated at $52^{\circ} \mathrm{C}$ for $5 \mathrm{~h}$.

The interfacial behaviour of the two proteins can be understood in part by considering the hydropathy profiles. These are shown in Figure 10. For lysozyme, the three-point average and the nine-point average of hydropathy suggest that broad hydrophilic and hydrophobic regions exist, comprising between 20 and 50 amino acids in proximity. For $\beta$-lactoglobulin, especially in the middle of the protein's sequence, the three-point average shows extreme excursions towards both hydrophilic and hydrophobic directions. This pattern suggests that the molecule may be subject to more distortion than lysozyme by the unbalance of surface forces.

In addition to the hydropathy, the two proteins have different internal strengths due to disulfide bridging which resists the 'tearing' forces arising from the hydropathy. Unfolding is dependent primarily upon the protein structure. Table 6 shows structural information for three proteins (including myoglobin) in their crystalline and adsorbed states. The extremes define a range of disulfide involvement ranging from myoglobin, deficient in cystein residues, to lysozyme, the well-characterized 'hard' protein containing four disulfide bonds, exhibiting little conformational flexibility in the native state.

The analysis of Table 6 was based upon a comparison, for each protein, of the area/molecule derived from the molecular dimensions obtained from the literature with that determined by the 'footprint' from neutron reflectivity studies at the air-water interface. The values of the area per
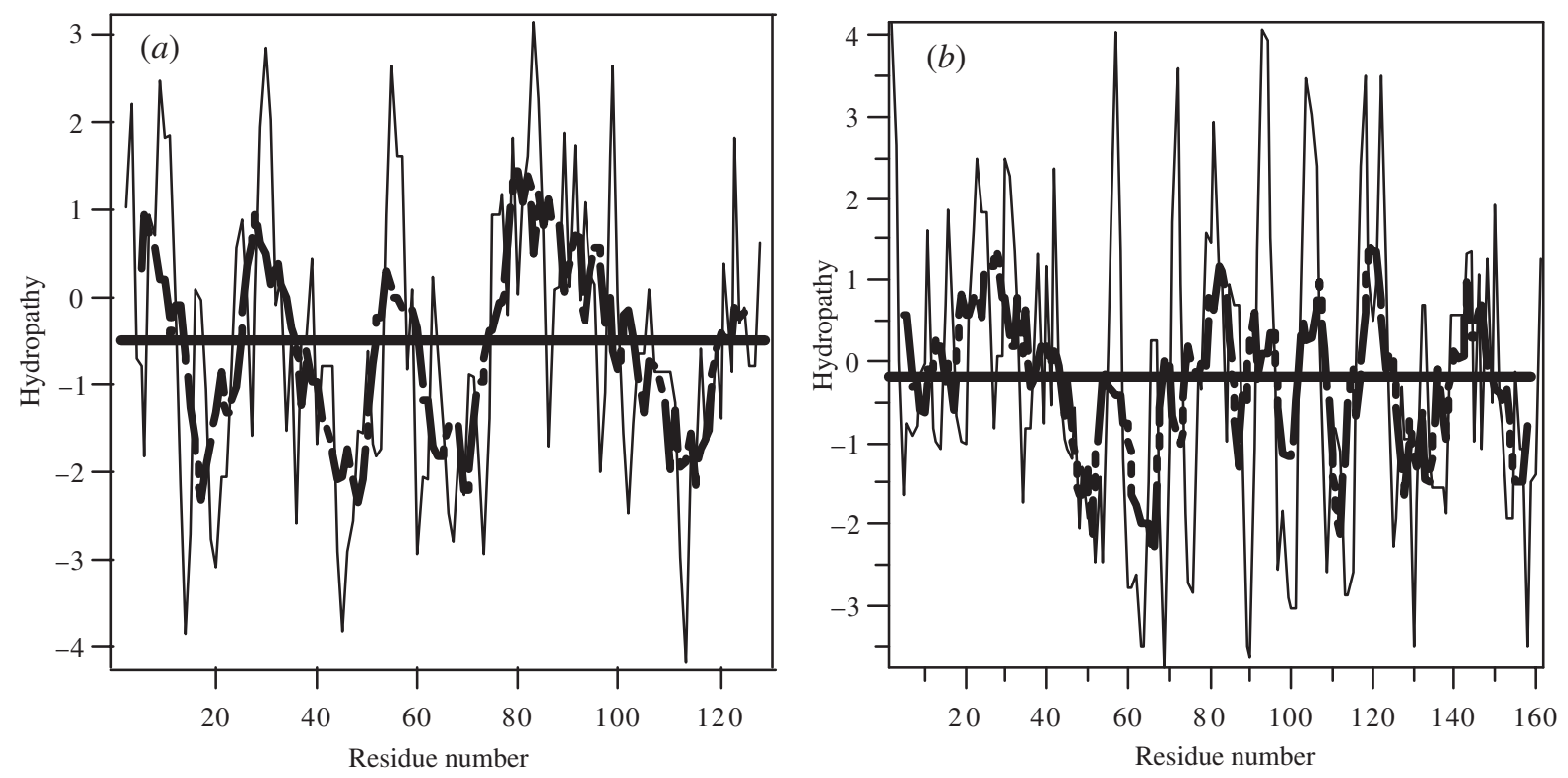

Fig. 10. Hydropathy profiles (nine-point and three-point averages) for: $(a)$ lysozyme; and (b) $\beta$-lactoglobulin. The thin line represents the three-point average, the dashed line represents the nine-point average, and the solid line represents the overall average. 
Table 6. Properties of materials used

\begin{tabular}{|c|c|c|c|}
\hline & Myoglobin & $\beta$-Lactoglobulin & Lysozyme \\
\hline Molecular weight (Da) & 16935 & 18265 (monomer) & 14296 \\
\hline Residues & 153 & 162 & 129 \\
\hline No. disulfide bonds & none & $2+1 \mathrm{SH}$ & 4 \\
\hline Secondary structure & $\alpha(100 \%)$ & $\alpha(10-15 \%)+\beta(50 \%)$ & $\alpha(25 \%)+\beta(45 \%)$ \\
\hline Molecule dimensions $\left(\AA^{3}\right)$ & $25 \times 35 \times 45^{\mathrm{A}}$ & $35.8 \times 35.8 \times 35.8^{\mathrm{B}}$ & $45 \times 30 \times 30^{C}$ \\
\hline $\begin{array}{l}\text { Area/molecule }\left(\AA^{2}\right) \\
\quad \text { (molecule dimensions) }\end{array}$ & 1575 & 1282 & 900 \\
\hline $\begin{array}{l}\text { Area/molecule }\left(\AA^{2}\right) \\
\quad \text { (neutron reflectivity) }\end{array}$ & 2300 & 1857 & 1363 \\
\hline Layer thickness $(\AA)$ & $16^{\mathrm{A}}$ & $36^{\mathrm{D}}$ & $48^{\mathrm{D}}$ \\
\hline \multicolumn{4}{|l|}{$\operatorname{SLD}\left(\AA^{-2}\right)$} \\
\hline No exchange & $1.81 \times 10^{-6}$ & $1.72 \times 10^{-6}$ & $2.00 \times 10^{-6}$ \\
\hline ACMW exchange & $1.94 \times 10^{-6}$ & $1.84 \times 10^{-6}$ & $2.15 \times 10^{-6}$ \\
\hline $\mathrm{D}_{2} \mathrm{O}$ exchange & $3.13 \times 10^{-6}$ & $2.99 \times 10^{-6}$ & $3.53 \times 10^{-6}$ \\
\hline
\end{tabular}

${ }^{A}$ See Ref. [1]. ${ }^{B}$ See Ref. [22]. ${ }^{C}$ See Ref. [23]. ${ }^{\text {D }}$ A. Perriman, unpublished data.

molecule from the reflectivity study were determined by application of the following relationship:

$$
\text { area } / \text { molecule }=\frac{\sum b_{\text {protein }}}{\tau \times \rho_{b}}
$$

where $\Sigma b_{\text {protein }}$ is the sum of the scattering lengths of the elements which comprise the protein $(\AA)$; $\tau$ is the thickness of the layer $(\AA)$; and $\rho_{b}$ is the measured scattering length density of the layer $\left(\AA^{-2}\right)$. For $\beta$-lactoglobulin, $\rho_{b}=0.75 \times 10^{-6} \AA^{-2}$; for lysozyme, $\rho_{b}=1.12 \times 10^{-6} \AA^{-2}$. A comparison of the area/molecule to those obtained by neutron reflectivity show that the area occupied by protein molecules at the fluid interface are ca. 1.5 times larger than in the native molecular state. These values indicate that each protein has been deformed at the air-water interface. The calculated SLD for the most rigid protein, lysozyme, in ACMW assuming substitution is $2.15 \times 10^{-6} \AA^{-2}$. The low, measured value of $1.12 \times 10^{-6} \AA^{-2}$ indicates that there is a significant proportion of sub-phase associated with the protein at the interface.

The layer thicknesses presented in Table 6 show that the susceptibility to deformation at the interface decreases in the order: myoglobin $>\beta$-lactoglobulin $>$ lysozyme. The layer thickness determined for myoglobin at the air-water interface, at $16 \AA$, is thinner than expected from the smallest dimension of the unit cell or the molecular diameter calculated from the unit cell dimensions. This thickness corresponds to approximately the thickness of a single $\alpha$-helix and suggests a substantial loss of tertiary structure. The layer thickness determined for $\beta$-lactoglobulin (36 $\AA$ ) and lysozyme ( $48 \AA$ ) are in agreement with literature values of their molecular dimensions $\left(35.8^{[22]}\right.$ and $45 \AA^{[23]}$ respectively) and also with values obtained by neutron $\left(37 \AA^{[24]}\right)$ and X-ray $\left(45 \AA^{[23]}\right)$ reflectivity at a solid surface.

\section{Fitting the 'Order Parameter' for Surface Denaturation}

In order to fit the change in the protein layer thickness as a function of temperature and to extract thermodynamic parameters for the denaturation process, we first of all assume that denaturation is an equilibrium between two states only whose proportions change between 25 and $70^{\circ} \mathrm{C}$. These are the folded and the unfolded states of the protein. We furthermore assume that since the heating process was slow, the protein achieves an equilibrium degree of unfolding at any particular temperature where neutron reflectivity measurements were taken.

We furthermore assume that the reflectivity measurement is an average value of the thickness associated with the superposition of the different states of the protein at a particular temperature. The fitting process therefore assumes that the thickness of a folded (native) protein is the minimum measured thickness, $d_{\mathrm{n}}$, and that the thickness of an unfolded protein is the maximum measured thickness, $d_{\mathrm{u}}$. If $d_{1}$ is the measured layer thickness from neutron reflectivity, $F_{\mathrm{u}}$ is the fraction of unfolded proteins, Equation (6).

$$
F_{\mathrm{u}}=\frac{d_{\mathrm{n}}-d_{1}}{d_{\mathrm{n}}-d_{\mathrm{u}}}
$$

The equilibrium constant between the folded and the unfolded states is then given by:

$$
K_{\mathrm{eq}}=\frac{F_{\mathrm{u}}}{\left(1-F_{\mathrm{u}}\right)}
$$

Following the approach based on that of DeKoster et al., ${ }^{[16]}$ we show that the fraction of unfolded protein, $F_{u}$, at a particular temperature, $T$, is:

$$
F_{\mathrm{u}}=\frac{i_{\mathrm{bt}}+i_{\mathrm{at}} \cdot \exp \left(\left(\frac{\Delta H}{R}\right)\left(\frac{1}{T_{\mathrm{m}}}-\frac{1}{T}\right)\right)}{1+\exp \left(\left(\frac{\Delta H}{R}\right)\left(\frac{1}{T_{\mathrm{m}}}-\frac{1}{T}\right)\right)}
$$


where $i_{\mathrm{bt}}$ is the intercept before the transition; $i_{\mathrm{at}}$ the intercept after transition; $T_{\mathrm{m}}$ the midpoint of denaturation, $\Delta H$ the enthalpy of unfolding and $R$ the gas constant $(1.987 \mathrm{cal}$ $\mathrm{mol}^{-1} \mathrm{~K}^{-1}$ ). This approach was used to fit $d_{1}$ versus $T$ data for lysozyme (Fig. 4) and for $\beta$-lactoglobulin (Fig. 9). The $F_{\mathrm{u}}$ versus $T$ profiles and the fitted curves for lysozyme and $\beta$-lactoglobulin are displayed in Figures 11 and 12 respectively. Though a limited data set in each case caused some uncertainty in the fit to the data, the simulated profiles provide a reasonable guide to the energetics of denaturation and their relationship to the structural properties of the two globular proteins. The values derived from the fit to the data with the model described in Equation (8) are $\Delta H$ $70 \mathrm{kcal} \mathrm{mol}^{-1}$ and $T_{m} 40^{\circ} \mathrm{C}$ for lysozyme. For $\beta$-lactoglobulin the values are $50 \mathrm{kcal} \mathrm{mol}^{-1}$ and $52^{\circ} \mathrm{C}$ respectively.

The values of $\Delta H$ for lysozyme and $\beta$-lactoglobulin determined in this study fall within the range defined by the

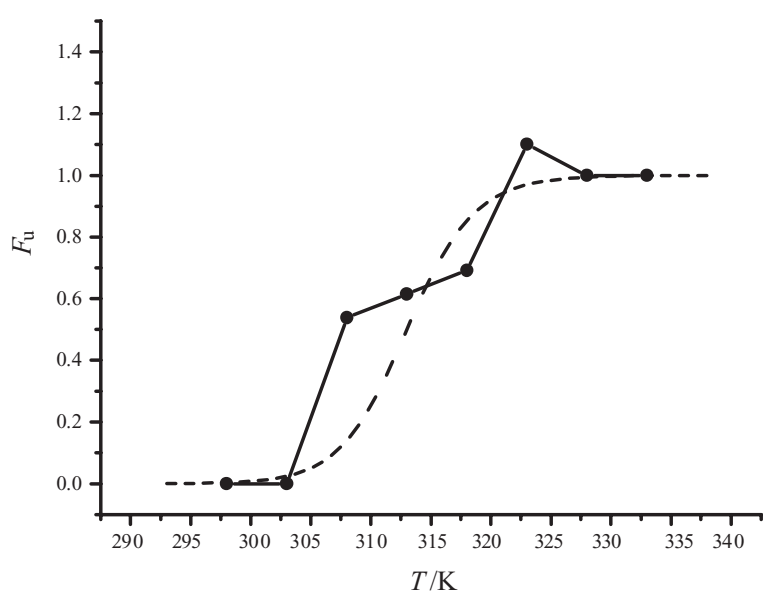

Fig. 11. Fraction of unfolded $\left(F_{\mathrm{u}}\right)$ lysozyme versus temperature $(T)$ in $1 \mathrm{mg} \mathrm{mL}-1$ lysozyme solution, pH 2.0 (data from Fig. 4). The broken line represents the simulated curve in accordance with a denaturation process that follows a two-state model.

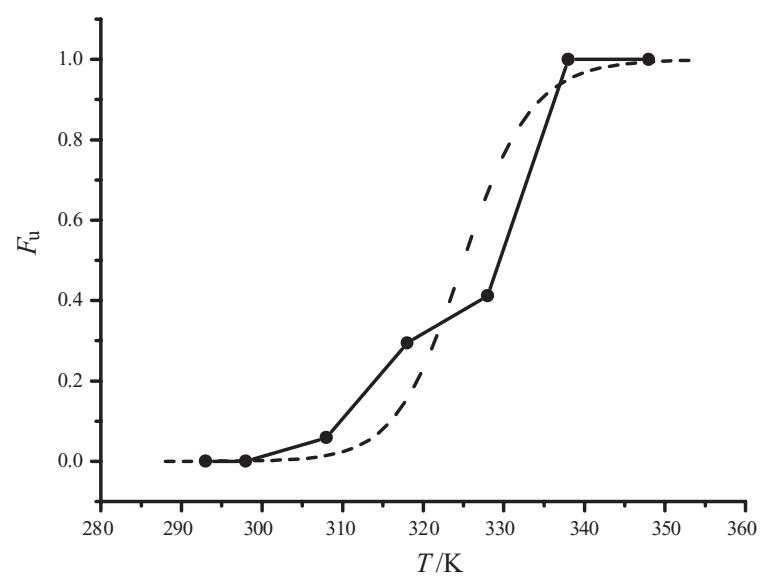

Fig. 12. Fraction of unfolded $\left(F_{\mathrm{u}}\right) \quad \beta$-lactoglobulin versus temperature $(T)$ in $1 \mathrm{mg} \mathrm{mL}^{-1} \beta$-lactoglobulin solution, $\mathrm{pH} 7.0$ (data from Fig. 9). The broken line represents the simulated curve in accordance with a denaturation process that follows a two-state model. denaturation of ribonulease A, $96 \mathrm{kcal} \mathrm{mol}^{-1[16]}$ and turkey ovomucoid third domain, $40.8 \mathrm{kcal} \mathrm{mol}^{-1} \cdot{ }^{[25]}$ These values were determined by a similar analytical protocol for data acquired from spectroscopic responses to thermal and chemical denaturation of these proteins. We note that Ribonulease $\mathrm{A}^{[26]}$ (124 amino acid residues) and hen egg white lysozyme ${ }^{[26]}$ (129 amino acid residues) both contain four disulfide linkages. In addition, their enthalpies of unfolding are greater than those of turkey ovomucoid (56 amino acid residues), which contains three disulfide bridges, and $\beta$-lactoglobulin (162 amino acid residues), which contains two disulfide bridges and one free thiol group. The enthalpy change between folded and unfolded states, $\Delta H$, consists of dispersion forces, electrostatic interactions, van der Waals potentials and hydrogen bonding within the protein. Of these interactions, the major contribution to the enthalpy of unfolding comes from the disruption of van der Waals interactions between amino acid groups packed in the native state. ${ }^{[27]}$ If we assume that $\beta$-lactoglobulin and lysozyme are fully unfolded under the conditions of our experiment, the higher $\Delta H$ value determined for lysozyme may be reconciled in structural terms where a greater number of disulfide linkages results in a more tightly bound protein.

\section{Conclusions}

In this study the structural distortions accompanying denaturation of the globular proteins hen egg white lysozyme and $\beta$-lactoglobulin at the air-water interface are shown. An analytical protocol for extracting thermodynamic information, based upon film thickness measurements on denaturation process, is also developed.

(i) For relatively low $\left(1 \mathrm{mg} \mathrm{mL}^{-1}\right)$ and high $\left(10 \mathrm{mg} \mathrm{mL}^{-1}\right)$ concentrations of lysozyme solutions at $\mathrm{pH} \mathrm{2,} \mathrm{film}$ thickness and surface excess measurements increase with increasing temperature. At low lysozyme solution loading, where monolayer behaviour dominates, the temperature of denaturation was $45^{\circ} \mathrm{C}$, lower than that reported for the unfolding process in bulk solution. At high solution loading, the temperature of denaturation was $53^{\circ} \mathrm{C}$, considerably higher than for the monolayer system.

(ii) With the exception of the two-layer structure at $\mathrm{pH} 2$ and $65^{\circ} \mathrm{C}$, low $\mathrm{pH}$ and neutral $\mathrm{pH}$ solutions of $1 \mathrm{mg} \mathrm{mL}^{-1} \quad \beta$-lactoglobulin solutions displayed monolayer behaviour for the temperature range studied $\left(25-65^{\circ} \mathrm{C}\right)$ for solutions of this protein. At $\mathrm{pH} 7$, where $\beta$-lactoglobulin dimers predominate, film densification and ingress of the sub-phase with increasing temperature indicated a partial unravelling of the protein structure above $55^{\circ} \mathrm{C}$.

(iii) An analytical protocol involving the fraction of unfolded protein $\left(F_{\mathrm{u}}\right)$ as a function of temperature $(T)$, determined from the layer thickness measurements for both lysozyme and $\beta$-lactoglobulin, is described. For each case, a plot of $F_{\mathrm{u}}$ versus $T$ shows sigmoidal behaviour. The profiles can be simulated by a model in which denaturation is considered to be an 
equilibrium between two states only, whose proportions change between the extremes of the temperatures studied. The enthalpy of unfolding, $\Delta H$, and the midpoint of unfolding, $T_{\mathrm{m}}$, can be derived from the simulation. For lysozyme, $\Delta H$ was $70 \mathrm{kcal}$ $\mathrm{mol}^{-1}$ and $T_{\mathrm{m}} 40^{\circ} \mathrm{C}$. For $\beta$-lactoglobulin, the values were $50 \mathrm{kcal} \mathrm{mol}^{-1}$ and $52^{\circ} \mathrm{C}$. These values are significantly lower for proteins in bulk solution that have a similar number of disulfide bridges and may indicate, by the methodology described in this paper, that the enthalpy contribution of the surface toward denaturation can be determined.

\section{Acknowledgement}

Neutron reflectrometry experiments were funded through the Access to Major Research Facilities Fund, administered by the Australian Science and Technology Organisation.

\section{References}

[1] S. A. Holt, D. J. McGillivray, S. Poon, J. W. White, J. Phys. Chem B 2000, 104, 7431

[2] (a) F. MacRitchie, A. E. Alexander, J. Colloid Sci. 1963, 18, 453; (b) F. MacRitchie, A. E. Alexander, J. Colloid Sci. 1963, 18, 458; (c) F. MacRitchie, A. E. Alexander, J. Colloid Sci. 1963, 18, 464.

[3] (a) D. E. Graham, M. C. Phillips, J. Colloid Interface Sci. 1979, 70, 403; (b) D. E. Graham, M. C. Phillips, J. Colloid Interface Sci. 1979, 70, 415; (c) D. E. Graham, M. C. Phillips, J. Colloid Interface Sci. 1979, 70, 427.

[4] C. Malmsten, J. Colloid Interface Sci. 1994, 166, 333.

[5] P. Billsten, M. Wahlgren, T. Arnebrant, J. McGuire, H. Elwing, J. Colloid Interface Sci. 1995, 175, 77.

[6] J. R Lu, T. J. Su, R. K Thomas, J. Penfold, J. R Webster, J. Chem. Soc., Faraday Trans. 1998, 94, 3279.
[7] J. R. Lu, T. J. Su, P. N. Thirtle, R. K. Thomas, A. R. Rennie, R. Cubitt, J. Colloid Interface Sci. 1998, 206, 212.

[8] A. S. Brown, S. A. Holt, P. A. Reynolds, J. Penfold, J. W. White, Langmuir 1998, 14, 5532.

[9] J. L. Ruggles, S. A. Holt, P. A. Reynolds, J. W. White, Langmuir 2000, 16, 4613.

[10] F. Abelès, Ann. Phys. (Paris) 1948, 3, 504.

[11] J. Penfold, in Neutron, X-Ray and Light Scattering (Eds P. Lidner, Th. Zemb) 1991, 223

[12] P. Timmins, 2001, unpublished results.

[13] S. J. Perkins, Eur. J. Biochem. 1986, 157, 169.

[14] T. J. Su, J. R. Lu, R. K. Thomas, Z. F. Cui, J. Penfold, Langmuir 1998, 14,438 .

[15] L. A Morozova-Roche, J. Zurdo, A. Spencer, W. Noppe, V. Receveur, D. B. Archer, M. Joniau, C. M. Dobson, J. Struct. Biol. 2000, 130, 339.

[16] G. T. DeKoster, A. D. Robertson, Biophys. Chem. 1997, 64, 59.

[17] T. Lefèvre, M. Subirade, Int. J. Biol. Macromol. 2000, 28, 59.

[18] R. Pickersgill, K. Varvill, S. Jones, B. Perry, B. Fischer, I. Henderson, S. Garrard, I. Sumner, P. Goodenough, FEBS Lett. 1994, 347, 199.

[19] R. J. Green, I. Hopkinson, R. A. L. Jones, Langmuir 1999, 15, 5102.

[20] K. L. Fuller, S. G. Roscoe, in Food Proteins: Structure-Function Relationships (Eds R. Y. Yada, R. L. Jackman, J. A. L. Smith) 1994, pp. 143-162 (Blackie Academic and Professional Publishers: London).

[21] A. H. Clarke, C. D. Tuffnell, Int. J. Peptide Protein Res. 1980, 16, 339.

[22] M. Cornec, D. Cho, G. Narsimhan, J. Colloid Interface Sci. 1999, $214,129$.

[23] R. Kayushina, Y. Lvov, N. Stepina, V. Belyaev, Y. Khurgin, Thin Solid Films 1996, 284-285, 246.

[24] R. J. Marsh, R. A. L. Jones, M. Sferrazza, J. Penfold, J. Colloid Interface Sci. 1999, $218,347$.

[25] L. Swint, A. D. Robertson, Protein Sci. 1993, 2, 2037.

[26] J-Y. Chang, L. Li, FEBS Lett. 2002, 511, 73.

[27] G. I Makhatadze, P. L. Privalov, Biophys. Chem. 1994, 51, 291. 